\title{
PENGEMBANGAN PERANGKAT LUNAK PENGOLAHAN CITRA UNTUK PENENTUAN SIFAT FISIS BATUAN
}

\author{
Afdal \\ Jurusan Fisika FMIPA Universitas Andalas \\ Kampus Unand, Limau Manis, Padang, 25163 \\ e-mail: afdal@fmipa.unand.ac.id
}

\begin{abstract}
ABSTRAK
Interpretasi data geofisika seperti dalam geofisika eksplorasi, pertambangan, teknik, dan geofisika lingkungan membutuhkan pengetahuan tentang sifat fisis batuan. Beberapa sifat fisis batuan dapat diperoleh dengan teknik pengolahan citra digital. Dalam penelitian ini dikembangkan perangkat lunak pengolahan citra digital untuk penentuan sifat fisis batuan. Perangkat lunak pengolahan citra yang dikembangkan dapat digunakan untuk menentukan beberapa sifat fisis batuan seperti karakteristik pori dan rekahan. Karakteristik pori terdiri atas porositas dan dimensi fraktal. Sedangkan karakteristik rekahan terdiri atas distribusi panjang rekahan, densitas dan dimensi fraktal.
\end{abstract}

Kata kunci : pengolahan citra, sifat fisis batuan

\begin{abstract}
Interpretation of geophysics data such as in exploration and environmental geophysics, and mining needs information about physical properties of rocks. Some of rocks physical properties can be determined from digital image. An image processing software to identify physical properties of rock from its digital image has been developed in this research. The software can be used to identify pore characteristics (porosity and fractal dimension) and fracture characteristics (length, density, fractal dimension).
\end{abstract}

Key words: image processing, physical properties of rock

\section{PENDAHULUAN}

Informasi rinci tentang kondisi bawah permukaan bumi (seperti porositas, permeabilitas, orientasi rekahan dinding bor, tinggi permukaan air) penting dalam pengembangan, manajemen, karakterisasi serta pemeliharaan sumber minyak dan air (Li, 2003). Geofisika lubang bor (borehole geophysics) menyediakan cara untuk mendapatkan informasi tersebut.

Ada banyak metode geofisika lubang bor yang biasa digunakan selama ini, seperti pengukuran resistivitas, akustik dan logging elektromagnet. Tetapi semua metode tersebut merupakan metode tidak langsung. Dalam metode tidak langsung, informasi (besaran) tentang kondisi lubang bor yang diinginkan tidak diperoleh secara langsung, tetapi melalui data lain yang diproses sampai diperoleh informasi yang diinginkan tersebut. Sebagai contoh, metode radar lubang bor digunakan untuk mendeteksi daerah rekahan, tetapi informasi rekahan tidak diperoleh langsung. Data yang diperoleh langsung adalah waktu tempuh gelombang. Data ini kemudian diolah untuk mendapatkan karakteristik rekahan. Metode tidak langsung sudah cukup baik, tetapi beberapa hal seperti kemampuan alat, metode pengolahan dan interpretasi data akan mempengaruhi keakuratan hasil. 
Untuk mengatasi hal tersebut maka diperlukan suatu metode atau pendekatan baru dimana besaran-besaran yang diinginkan seperti sifat fisis batuan dapat diamati secara langsung. Dengan metode penyelidikan langsung ini maka hasil yang diperoleh akan lebih baik dan akurat. Kemajuan teknologi komputasi telah mendorong perluasan penerapan teknik pengolahan citra digital di banyak bidang, termasuk geofisika dan dapat digunakan sebagai bagian dari metode penyelidikan langsung tersebut.

Metode penyelidikan langsung tersebut terdiri atas tiga bagian yaitu: pengembangan perangkat lunak pengolahan citra digital, teknik penyiapan sampel dan pengembangan perangkat keras akuisisi citra batuan. Di sini yang dilakukan hanya pengembangan perangkat lunak pengolahan citra saja.

\section{METODOLOGI}

\subsection{Perancangan Program}

Proses-proses penanganan citra seperti teknik pengambilan yang tidak benar, pengubahan bentuk dan pengiriman dapat menyebabkan citra yang diperoleh memiliki kualitas yang kurang baik. Pada citra seperti itu ada informasi mengenai citra tersebut yang hilang atau tertutupi. Citra seperti itu perlu diperbaiki sehingga menjadi lebih mudah diinterpretasi dan digunakan lebih lanjut. Dalam penulisan ini perbaikan kualitas citra diperlukan agar informasi yang ada pada permukaan batuan dapat dilihat dengan lebih jelas. Secara umum, perbaikan kualitas citra adalah pemberian tekanan pada informasi tertentu dari suatu citra. Disini proses perbaikan kualitas citra yang akan dilakukan adalah pengaturan kecerahan dan perataan histogram (histogram equalization).

Setelah proses perbaikan dilakukan pada sebuah citra batuan, maka citra tersebut sudah dapat dianalisis untuk ditentukan sifat fisisnya. Penentuan sifat fisis batuan dengan analisis citra digital memerlukan format citra tertentu. Untuk mendapatkan citra dengan format tersebut maka perangkat lunak ini dilengkapi dengan fitur-fitur khusus seperti edge detection dan thresholding. Untuk menentukan karakteristik pori batuan dari citra digital, pertama tentukan kriteria pori berdasarkan warna. Lalu ubah format citra menjadi citra biner, pori menjadi berwarna putih dan yang bukan pori (butiran) menjadi berwarna hitam. Selanjutnya program dapat menghitung porositas dan dimensi fraktal dari citra sampel batuan tersebut. Prosedur ini dapat dilihat pada Gambar 1.

\subsection{Validasi}

Selanjutnya perangkat lunak yang dihasilkan divalidasi dengan melakukan karakterisasi terhadap beberapa sampel citra batuan. Hasilnya ditampilkan pada Tabel 1.

Tabel 1. Hasil perbandingan penghitungan dimensi fraktal antara program dan referensi.

\begin{tabular}{|c|c|c|}
\hline Sampel & $\begin{array}{c}\text { Dimensi Fraktal } \\
\text { (Nakamura, 2001) }\end{array}$ & $\begin{array}{c}\text { Dimensi Fraktal } \\
\text { (Hasil Program) }\end{array}$ \\
\hline Njm-001 & 1,09 & 1,16 \\
\hline Njm-002 & 1,21 & 1,22 \\
\hline Njm-004 & 1,24 & 1,31 \\
\hline Njm-005 & 1,47 & 1,47 \\
\hline Njm-007 & 1,41 & 1,45 \\
\hline Njm-006 & 1,50 & 1,49 \\
\hline
\end{tabular}




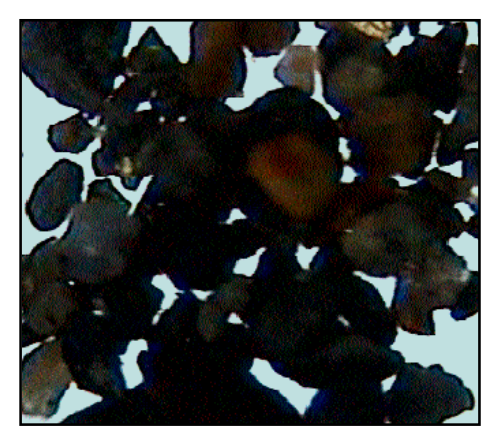

(a)

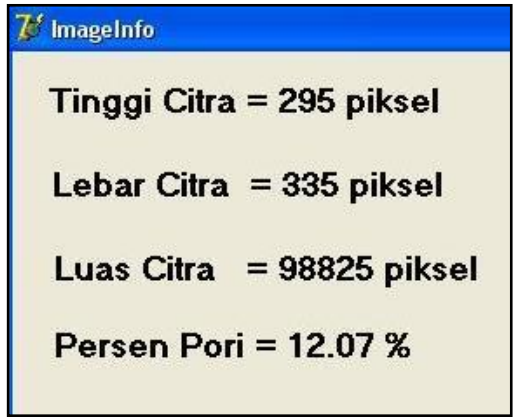

(c)

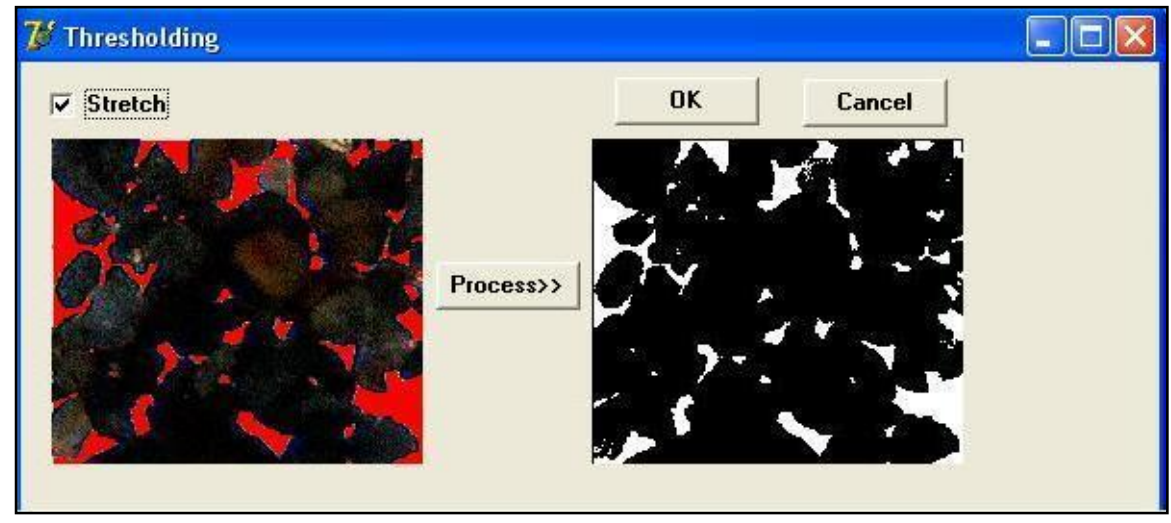

(b)

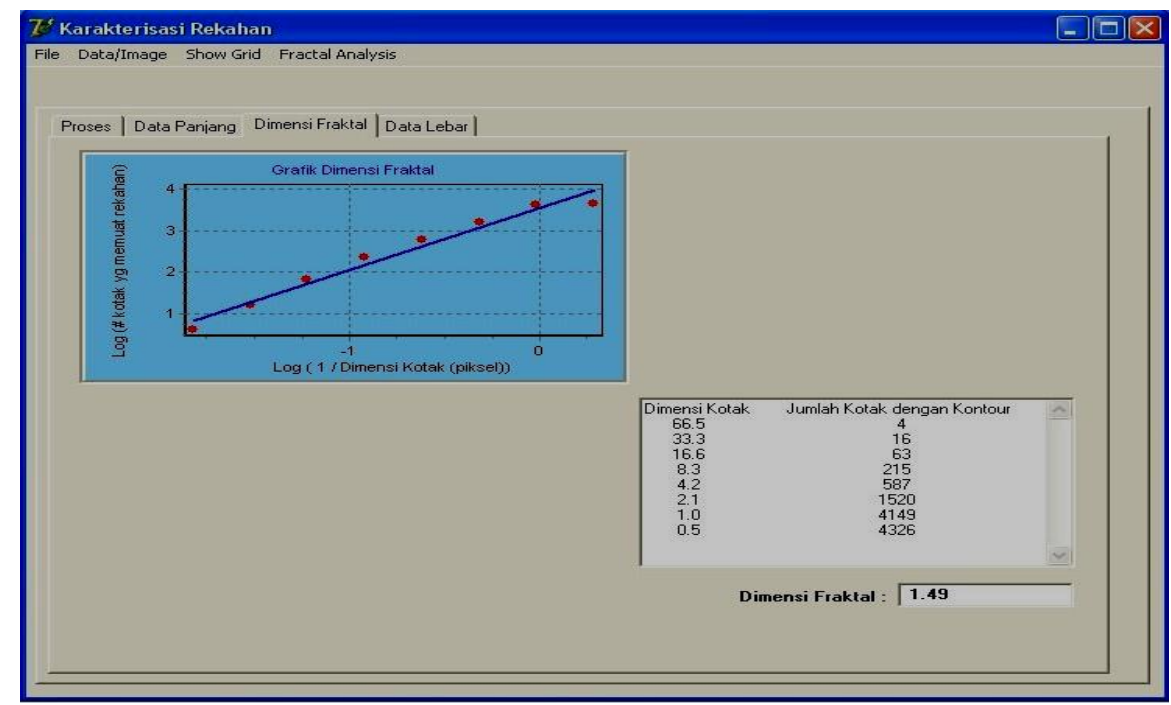

(d)

Gambar 1 Prosedur penentuan karakteristik pori.

(a) Citra awal. (b) Pemilihan warna pori. (c) Karakteristik pori

d) Perhitungan dimensi fraktal 


\section{HASIL DAN DISKUSI}

Selanjutnya program ini digunakan untuk mengkarakterisasi pori beberapa sampel citra batuan. Perangkat lunak yang dibuat dapat menentukan karakteristik pori batuan, yaitu porositas dan dimensi fraktal, secara kuantitatif. Dari penerapan pada beberapa sampel juga ditemukan bahwa dimensi fraktal turun terhadap porositas. Hubungannya adalah seperti Gambar 2.

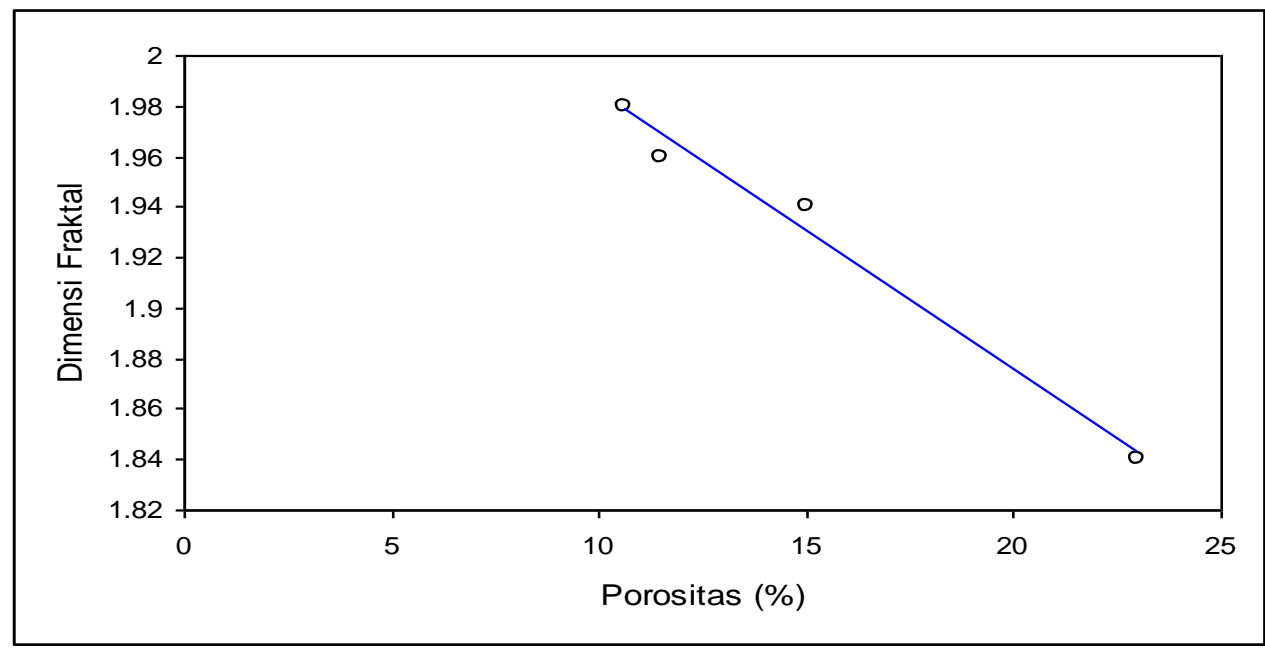

Gambar 2 Hubungan dimensi fraktal dengan porositas
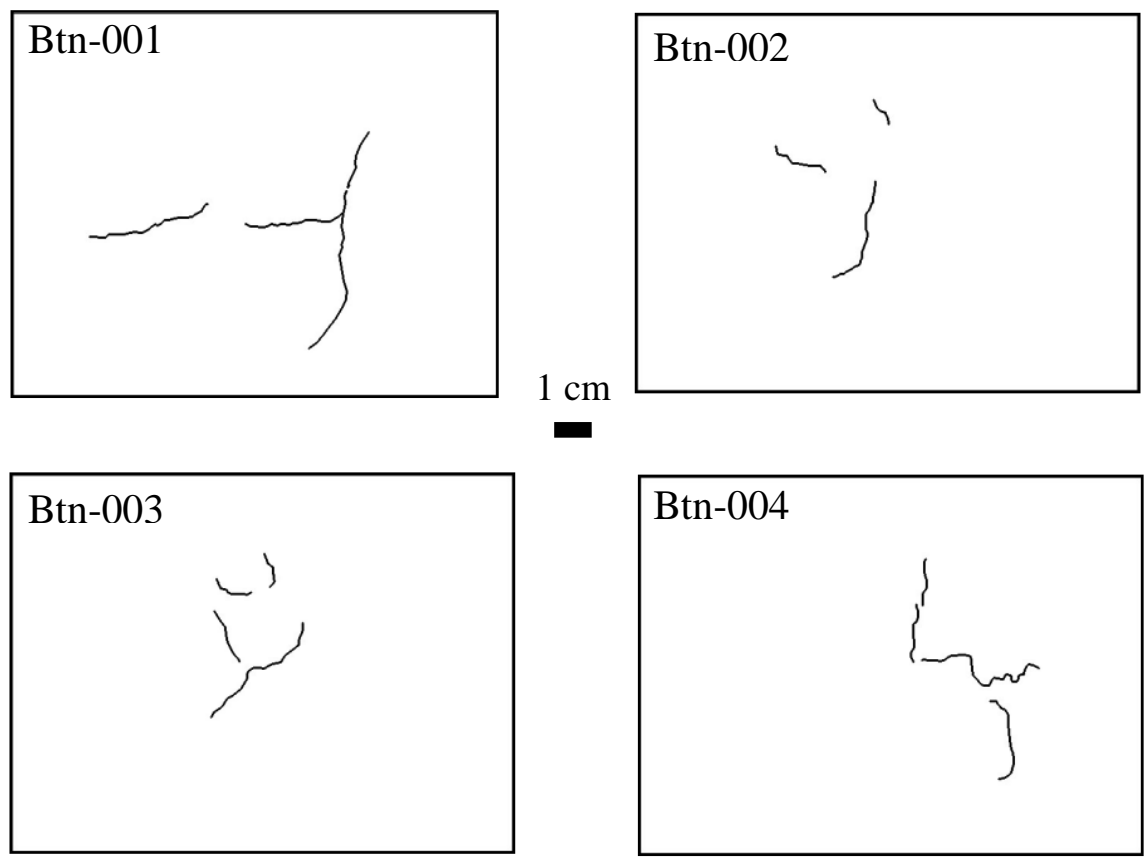

Gambar 3 Pola rekahan sampel batuan yang diambil di sekitar sesar Lembang, Jawa Barat. 
Selanjutnya program ini digunakan untuk mengkarakterisasi rekahan batuan. Sampel yang digunakan adalah citra rekahan pada batuan dan dinding singkapan di sekitar sesar Lembang, Jawa Barat. Pola rekahan sampel dan hasil identifikasinya dapat dilihat pada Gambar 3 dan 4. Hasil perhitungan dimensi fraktal dan densitas rekahan untuk semua citra rekahan batuan dan dinding singkapan tersebut dapat dilihat dalam Tabel 1. Dari Gambar 5 dapat dilihat menunjukkan bahwa dimensi fraktal sebanding dengan densitas rekahan.

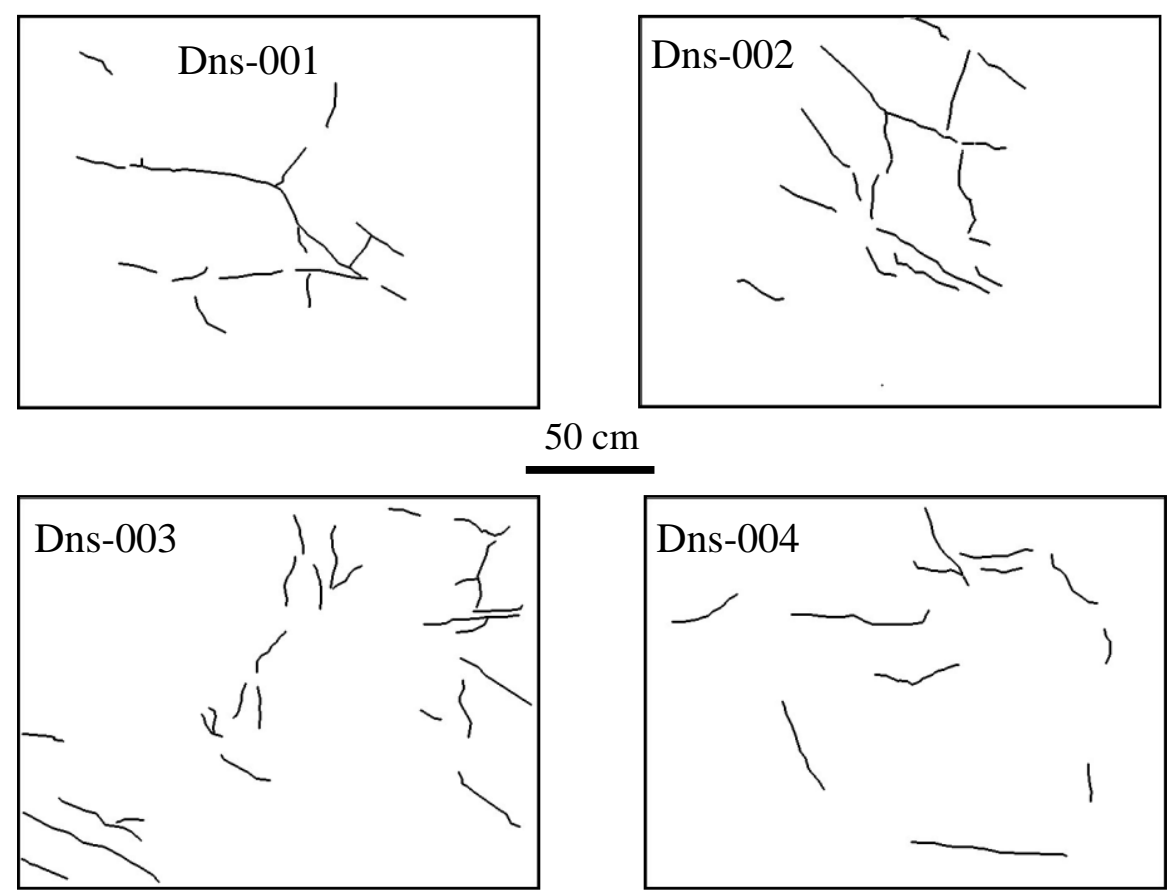

Gambar 4 Pola rekahan dinding singkapan yang diambil di sekitar sesar Lembang, Jawa Barat.

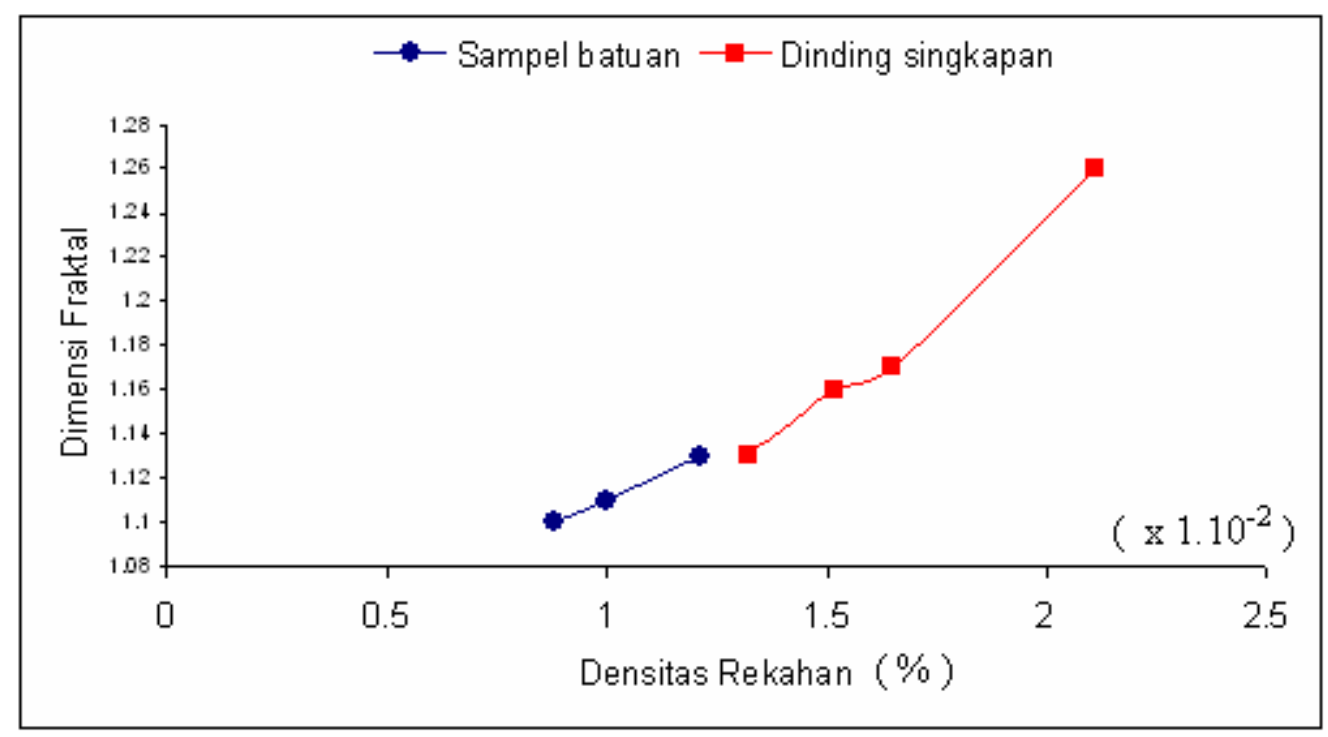

Gambar 5 Hubungan dimensi fraktal dengan densitas rekahan 


\section{KESIMPULAN}

a) Metode analisis citra digital menawarkan suatu cara alternatif dalam penentuan sifat fisis batuan.

b) Geometri fraktal menyediakan suatu cara untuk menganalisis struktur rekahan batuan yang rumit.

c) Porositas dan rekahan batuan menunjukkan sifat fraktal.

d) Dimensi fraktal turun terhadap porositas

e) Dimensi fraktal sebanding dengan densitas rekahan.

\section{DAFTAR PUSTAKA}

1. Li, K., Horne, R.N. (2003), Fractal Characterization of the geysers rock, Geothermal Resources Council Transaction, 27.

2. Nakamura, N., Nagahaka, H. (2001), Change in magnetic and fractal properties of fractured granites near the Nojima Fault, Japan, The Island Arc, 10, 486 - 494.

3. Rosenfeld, A., Kak, A.C., (1976), Digital Picture Processing, Academic Press, New York.

4. Schön, J.H., (1996), Physical Properties of Rocks, Fundamental and Principles of Petrophysics, dalam Handbook of Geophysical Exploration Seismic Exploration, Volume 18, Helbig, K., Treitel, S., Editor, Pergamon, Oxford. 